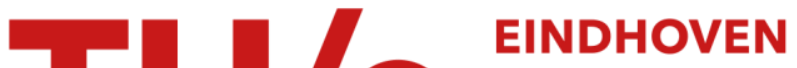 UNIVERSITY OF TECHNOLOGY
}

\section{A five-year review of methods, purposes and domains of the international symposium on wearable computing}

\section{Citation for published version (APA):}

Nachtigall, T., Tetteroo, D., \& Markopoulos, P. (2018). A five-year review of methods, purposes and domains of the international symposium on wearable computing. In ISWC 2018 - Proceedings of the 2018 ACM International Symposium on Wearable Computers (pp. 48-55). Association for Computing Machinery, Inc. https://doi.org/10.1145/3267242.3267272

DOI:

10.1145/3267242.3267272

Document status and date:

Published: 08/10/2018

\section{Document Version:}

Accepted manuscript including changes made at the peer-review stage

\section{Please check the document version of this publication:}

- A submitted manuscript is the version of the article upon submission and before peer-review. There can be important differences between the submitted version and the official published version of record. People interested in the research are advised to contact the author for the final version of the publication, or visit the $\mathrm{DOI}$ to the publisher's website.

- The final author version and the galley proof are versions of the publication after peer review.

- The final published version features the final layout of the paper including the volume, issue and page numbers.

Link to publication

\section{General rights}

Copyright and moral rights for the publications made accessible in the public portal are retained by the authors and/or other copyright owners and it is a condition of accessing publications that users recognise and abide by the legal requirements associated with these rights.

- Users may download and print one copy of any publication from the public portal for the purpose of private study or research.

- You may not further distribute the material or use it for any profit-making activity or commercial gain

- You may freely distribute the URL identifying the publication in the public portal.

If the publication is distributed under the terms of Article $25 \mathrm{fa}$ of the Dutch Copyright Act, indicated by the "Taverne" license above, please follow below link for the End User Agreement:

www.tue.nl/taverne

Take down policy

If you believe that this document breaches copyright please contact us at:

openaccess@tue.nl

providing details and we will investigate your claim. 


\section{A Five-Year Review of Methods, Purposes and Domains of the International Symposium on Wearable Computing}

\author{
Troy Nachtigall \\ TU/Eindhoven \\ Eindhoven, The Netherlands \\ t.r.nachtigall@tue.nl
}

\author{
Daniel Tetteroo \\ TU/Eindhoven \\ Eindhoven, The Netherlands \\ d.tetteroo@tue.nl
}

\author{
Panos Markopoulos \\ TU/Eindhoven \\ Eindhoven, The Netherlands \\ p.markopoulos@tue.nl
}

\begin{abstract}
This paper presents a structured survey of 119 publications from the proceedings of the International Symposium on Wearable Computers (ISWC) from 2013 until 2017. This survey is based upon a classification schema used by many others in HCI research, originating in the field of Information Systems. After a pilot survey, the original classification schema was modified slightly to incorporate a more current perspective of wearables research. An extra dimension was added to the classification of research methods pertaining to the Research Domains, in order to provide a more insightful overview of the field. A survey of publications between the years 2013 to 2017 was completed by classifying the research method, purpose and domain with multiple coders. An analysis of the research methods and purposes, and domains of ISWC is presented. Additionally, the citation impact of ISWC publications is evaluated and compared over these dimensions. Current tendencies of the research presented at ISWC are identified with focus on the contextual setting of the research. Opportunities for future research at ISWC are identified.
\end{abstract}

\section{Author Keywords}

Survey, Research Method, Research Purpose, Research Domain, Wearable Computing

\section{ACM Classification Keywords}

H.5.2. Information interfaces and presentation (e.g., HCI): User Interfaces; Theory and methods.

\section{INTRODUCTION}

Over the past twenty-one years of the International Symposium of Wearable Computers (ISWC), the relevance of wearable computing in everyday life has grown significantly. Wearable technology is commonly found in watches [14] and other places on the body [24]. ISWC is a venue that has gathered researchers interested in the engineering, design and study of wearable technologies. The field of Wearable Computing is attracting increasing interest from scholars with diverse backgrounds. Given the interest in ISWC, it is important to reflect on the research methods used, the purposes of research studies, and the research domains addressed with these studies.

This survey is inspired by similar surveys carried out in the fields of Human-Computer Interaction: End User Development [16] Mobile HCI [7] and Children's HCI [5]. In their turn, these surveys were based upon a similar survey in Information Systems (IS) [22]. These surveys classify publications in these fields in terms of the different research methods they used and the research purposes; the derived knowledge about the prevalence of research methods and research purposes served to identify new possibilities for research areas and relatively unexplored directions.

For the present survey, we selected a survey period of five years, between the years 2013 to 2017 . The selected period and number of publications are comparable to other surveys in the HCI field. Additionally, we add a dimension of Research Domain to the survey to bring greater understanding to the trajectories of the ISWC conference.

\section{RESEARCH METHODS, PURPOSES AND DOMAINS}

Our survey's intent is to bring insight into the Research Methods, Purposes and Domains of ISWC. We started with the two dimensional scheme developed by Kjeldskov and Graham [7]. This is based on the research methods schema by Wynekoop and Conger [22], illustrated in Table 1, founded upon the research settings of Benbasat [1]. We chose this classification schema as it was previously used in similar survey $[5,7,16]$. However, these earlier surveys have all identified shortcomings with the classification scheme with regards to its applicability in their respective fields on inquiry. We also found shortcomings by means of an initial pilot survey.

\section{Pilot survey}

A pilot survey was conducted to understand what, if any, shortcomings might be found in the selected schema [5]. Five $\mathrm{PhD}$ researchers familiar with wearable computing classified 90 abstracts of ISWC publications from the period surveyed. A small number of papers were found to be difficult to classify. A need for clearer definitions that would better account for prototypes and design research was identified. For example, questions around papers such as $[4,9,15]$ indicate that a prototype can serve as normative documentation. Other publications, for example $[6,12,14]$ 
Table 1: Summary of research methods and settings (extracted from Wynekoop and Conger [22])

\begin{tabular}{|c|c|c|c|c|c|c|c|c|}
\hline \multirow{2}{*}{$\begin{array}{l}\text { Setting } \\
\text { Researh } \\
\text { Method }\end{array}$} & \multicolumn{3}{|c|}{ Natural Setting } & Artificial Setting & \multicolumn{4}{|c|}{ Environment Independent Setting } \\
\hline & Case Studies & Field Studies & Action Research & Laboratory Experiments & $\begin{array}{l}\text { Survey } \\
\text { Research }\end{array}$ & $\begin{array}{l}\text { Applied } \\
\text { Research }\end{array}$ & Basic Research & $\begin{array}{l}\text { Normative } \\
\text { Writing }\end{array}$ \\
\hline Use & $\begin{array}{l}\text { Description, } \\
\text { explanation, } \\
\text { developing } \\
\text { hypothesis }\end{array}$ & $\begin{array}{c}\text { Studying } \\
\text { Current } \\
\text { Practice, } \\
\text { Evaluating new } \\
\text { practice. }\end{array}$ & $\begin{array}{c}\text { Generate } \\
\text { Hypothesis/ } \\
\text { Theory, Testing } \\
\text { Hypothesis/ } \\
\text { Theory }\end{array}$ & $\begin{array}{c}\text { Controlled Experiments, Thoery/ } \\
\text { Product testing }\end{array}$ & $\begin{array}{l}\text { Collecting } \\
\text { descriptive data } \\
\text { from large } \\
\text { samples }\end{array}$ & $\begin{array}{c}\text { Product } \\
\text { Development, } \\
\text { Testing } \\
\text { Hypothesis/ } \\
\text { Concepts }\end{array}$ & Theory Building & $\begin{array}{l}\text { Description of } \\
\text { Practice, } \\
\text { Building } \\
\text { Frameworks }\end{array}$ \\
\hline
\end{tabular}

raise questions about design research not covered by the classification schema. Deeper questions about wearables $[10,17]$, and research prototypes $[3,13,20]$ were also raised. We used these insights to modify the definitions of research methods and purposes slightly.

\section{Refining the Classification Scheme}

Based upon the pilot survey, criticism of the classification schema and consideration of the kinds of prototypes in the publications, small changes are made to the research methods extracted from Wynekoop and Conger [22]. The changes are motivated by the following needs 1) to classify research that does not fit in the schema, 2) to better characterize research contributions, 3) to characterize domains and thus add more relevance to the classifications. Our survey makes minor edits to the schema definitions [7] and adds an additional dimension of domains survey. We maintained the eight research methods and five research purposes, but adapted the definitions for greater clarity. This meant adding context and societal implications that we see in papers $[2,4,9]$. This also meant replacing the dimension of Normative Writing with the dimension of Normative Documentation to add more space for prototypes $[4,14,19]$. The pilot revealed that in many of the ISWC publications we see a prototype that is being used as a form of research archetype [14]. We extended definition to accommodate for prototypes that can in themselves be a form of documentation. As many wearables become connected to the internet, services develop. We add service systems to the definitions to reflect this trend. We use the design research space framework by Koskinen et al. [8] to add context to many definitions. Additionally the embodied, situated and tangible nature [18] of wearable computing often makes situation and context important. We made efforts to change the schema as little as possible.

\section{Method}

Here we list the definitions we used to classify research methods with our changes to the original definition [7] in italics.

\section{Case Studies}

Case studies are intensive empirical studies of small numbers of entities, such as organizations, groups and individuals [7]. They have been defined by Yin as "empirical enquiries that investigate a contemporary phenomenon within its real-life context, especially when the boundaries between phenomenon and context are not clearly evident" [23]. Case study results are usually hard to generalize, given their origin in a specific case. However, they can provide rich insights into specific cases and are particularly suitable for hypothesis generation and explaining complex phenomena [16].

\section{Field Studies}

Field studies take place in the real world and therefore emphasize considerations of context and its influence. They range from (usually qualitative) ethnographic studies to (usually quantitative) field experiments. Compared to artificial settings they offer increased external validity, but offer limited or no control and can be laborious and complicated to conduct [16].

\section{Action Research}

Action research combines both action and research within the same process and aims at generating knowledge by improving practice, and improving practice by the application of knowledge. This includes learning by making using prototypes as a "Vehicle for inquiry" [21]. Typically, this implies researchers participating in the intervention or activity studied, simultaneously evaluating the results. The advantages are that help incorporate first-hand experience, and open up the possibility to apply theory to practice directly. Disadvantages are the limited generalisability and the laborious nature of action research [16].

\section{Lab Experiments}

All research that takes place in an artificial environment setting is qualified as lab experiment in the scheme of [19]. Typically, researchers use lab experiments to perform limit the influence of contextual factors upon the studied phenomena. Lab experiments range from true experiments with manipulation of independent variables, to loosely structured usability evaluations that summarise impressions and anecdotes afterwards. Lab experiments have the advantage that they are usually easier and cheaper to conduct compared to field studies, but might lack ecological validity [16].

\section{Survey Research.}

Research that systematically samples a population through questionnaires or interviews. Responses are collected directly and are assumed to be independent of the context of the survey. This research is typically applied for collecting large amounts of data and is relatively cheap to perform. On the other hand, survey research might incur a respondent bias, and is typically cross sectional, providing a snapshot image of a phenomenon, thus is not well suited for studying how processes evolve over time [16]. 


\section{Applied Research}

Applied research is defined as environment independent research based on intuition, experience, deduction and induction, used to analyse a specific research problem[7]. Typically, the desired outcome or goal is known, but the methods and techniques for achieving this goal are unknown. The advantages of applied research are that it is goaldirected, and that it typically leads to a product. On the downside, solutions might be not generalizable, or may not materialise at all [16].

\section{Basic Research}

Basic research is about developing theories and frameworks in situations where the problems are well known, but the methods and solutions are unknown. Such research is often time consuming and may fail to produce any result, but has the advantage of allowing for a high level of creativity in the search for solutions [16].

\section{Normative-Writings Documentation}

This category includes all writings, exhibitions, pictorials, exemplars and research archetypes that do not describe actual research, and deal with insights such as concept development, 'truth' writings or context development [7]. Examples are descriptions of future research directions, 'oeuvre'-writings that reflect on a longer period of research on a particular topic, and papers or artefacts that present an opinion, inspire, debate or intuitively correct ideas and concepts [16]. This provides a space for the discussions around archetypes of wearables and is based heavily on the idea of critical design [8]. This method is extended to provide more relevance for prototypes and other ways of documenting research.

\section{Purpose}

Here we list the research purposes used to classify the data with the changes to the classification schema [22] highlighted in Italic.

\section{Understanding}

Research aimed at understanding the particulars, context or societal implications of a phenomenon or space studied.

\section{Engineering}

Research aimed at the original development of a service system, tool or technology.

\section{Re-engineering}

Research aimed at the engineering of modifications or extensions to an existing service system, tool or technology.

\section{Evaluating}

Research aimed at the assessment, validation and assurance of tools, technology, models, service systems and frameworks.

\section{Describing}

Research aimed at describing exploring the ideal properties of a system or situation including the debate or discussion surrounding a topic.

\section{Domain}

Thematic categories were developed by clustering author keywords. Keywords that described generic terms such as HCI or Wearables were excluded. Keywords that identified methods were also excluded. We use the domains classification scheme to identify domains based upon the Author Keywords, Title and Abstracts for each publication. A very small number of papers contained no Author Keywords or failed to clearly describe a domain, Titles and Abstracts were used in this case. Also, many papers concerned algorithms, but we chose to consider developing algorithms as a method of research. The following resulting domains were identified at the ISWC conference:

Personal Activity Monitoring/Recognition, Inputs, Mobile, Textiles, Outputs, Smartwatch, Sensing, HUD, Haptics, Gesture, Group Activity Monitoring/Recognition, Design, Health, Order Picking, VR, Pedagogy, Table Tennis, Skiing, Olfaction, Navigation, Modelling, Assistive Technology, Animals, Tracking, Telepresence, Sleep, Self-defense, Security, Localization, Jewelry, Firefighting, Document Classification, Communication.

\section{CLASSIFICATION OF RESEARCH METHODS, RESEARCH PURPOSES AND DOMAINS IN WEARABLE COMPUTING}

This section presents a classification of all of the papers and technical notes (short papers) presented at ISWC from 2013 to 2017. We used ACM digital library as our reference. Technical notes were considered given that a majority of these articles do not go on to full papers but do contain relevant research methods, purposes and domains. These publications are documented in Appendix A. We considered including posters and adjunct proceedings in this survey, but decided against it as it is not always possible to understand what research methods are used for what research purpose and what the involved domains are. Additionally, it would be more difficult to compare to other surveys which examined full papers only.

The publications were coded individually on research method and purpose by coders to ensure survey validity. Publication order was randomized and coding was done in groups of five papers, after which classifications were compared to ensure coder alignment. Multiple responses to methods and purpose are permitted and several papers use multiple methods for multiple purposes. Those with intercoder classification disagreements were discussed, reread, and reclassified for consensus. Each coder's independent classifications was compared to the consensus classification. The inter-coder agreement for research methods was 0.753 and research purpose was 0.759 using Cohen's kappa (asymptotic standardised errors of 0.027). This is found to be sufficiently reliable to draw the results presented in the following section [11].

Finally, publications are coded for domains using author keywords. Individual codings were needed for a vast majority of papers as the Author Keyword were very 
Table 2: Research methods and purposes classification of publications at ISWC between 2013 and 2017.

\begin{tabular}{|c|c|c|c|c|c|c|c|c|}
\hline & Applied Research & Lab Expiriments & Field Studies & $\begin{array}{c}\text { Normative } \\
\text { Documentation }\end{array}$ & Survey Research & Case Studies & Action Research & Basic Research \\
\hline Engineering & $\begin{array}{c}1,2,3,4,6,7,8,10,11,12, \\
13,14,15,18,19,20,22, \\
23,24,25,26,27,28,30, \\
31,32,33,38,39,40,41, \\
42,45,47,49,50,53,54, \\
56,58,59,61,63,64,65, \\
66,67,68,69,70,71,73, \\
74,75,79,81,82,85,87, \\
88,89,90,91,92,93,95, \\
96,97,98,99,100,101 \\
102,103,104,105,106, \\
108,110,112,114,115,1 \\
16,117,119\end{array}$ & & 18 & & & & & \\
\hline Evaluating & 37 & $\begin{array}{c}3,5,7,8,9,10,11,12,14, \\
15,17,18,19,20,23,24, \\
26,27,28,30,32,33,34, \\
38,40,43,45,46,48,49, \\
50,51,53,58,59,61,63, \\
64,65,66,67,68,69,72, \\
74,75,76,77,78,80,82, \\
87,88,89,90,91,92,93, \\
95,96,97,98,99,100,1 \\
01,102,103,104,105,1 \\
06,108,110,111,112,11 \\
7,119\end{array}$ & $\begin{array}{c}1,9,13,22,25,29,31,39 \\
, 41,52,54,55,57,73,84 \\
, 85,87,101,112,115\end{array}$ & & & & & \\
\hline Understanding & $76,80,109$ & $\begin{array}{c}16,35,107,104,119,11 \\
3\end{array}$ & $47,60,115$ & $15,73,84,91$ & $44,62,86$ & 70,83 & 79 & 78,94 \\
\hline Describing & $6,52,59,80,81,85,106$ & $90,109,111,113$ & 56.60 & $21,37,62,76,116,118$ & 36 & 83 & & \\
\hline Re-engineering & $5,9,43,46,55,57,81$ & & & & & & & \\
\hline
\end{tabular}

descriptive of the work. For three papers that contained no Author Keywords and a single ambiguous paper, Abstracts and Titles made agreement between coders a simple process.

\section{Results}

In this section results of the survey are presented. Research methods and purposes are presented separately from research domains to limit complexity, make this survey comparable to similar surveys and because many methods and domains are often seen together as seen in Table 2.

\section{Research methods and purposes}

119 publications of papers and notes are classified from the past five years. This includes 20 publications from 2013, 21 from 2014, 30 from 2015, 21 from 2016 and 27 from 2017. Each publication may have multiple classifications. 40 classifications were made from publications in 2013, 39 from 2014, 56 from 2015, 46 from 2016 and 58 from 2017.

Out of the 119 considered publications only 18 have one classification meaning that it was possible to identify a singular method and singular purpose for each, 82 have two classifications and 19 have three classifications in the final consensus, meaning that more methods were applied or more than one purposes were served. In total we find 239 classifications over 119 papers - thus percentages will total over $100 \%$.

If we look at the classifications in Table 2 we see that most papers fall in to Applied research (106 out of 119 papers, $89 \%$ ) and Lab Experiments (86, 72\%). The prevalence of Applied Research and Lab Experiment methods is comparable to the other similar surveys in HCI [7]. Field studies are well represented with 26 papers $(22 \%)$. This is followed by Normative documentation with 10 papers $(8 \%)$, Survey research with 5 papers (4\%), Case Studies with 3 papers (3\%), Basic Research with 2 papers $(2 \%)$ and Action
Research with 1 paper (1\%). Most classifications fall in the Environment Independent setting (51\%) due to the applied research category; this is followed by Artificial research $(36 \%)$ and Natural research $(13 \%)$.

Evaluating is dominant in research purposes with 98 papers $(82 \%)$. Engineering is also well represented with 85 papers (71\%). These are followed by Understanding with 24 papers (20\%), Describing with 22 papers $(18 \%)$ and Re-engineer with 10 papers $(8 \%)$.

There is a significant clustering of classifications and a relationship significance between classifications. (AP-EN) Applied Research for Engineering includes 84 publications (71\%). This links strongly to (LE-EV) Lab experiments for Evaluating with 62 publications (52\%) sharing (AP-EN) Applied Research for Engineering. Consider that 14 publications (12\%) use (FS-EV) Field studies for Evaluation along with (AP-EN) Applied Research for Engineering. If we also include Applied Research for Re-Engineering with 10 publications $(8 \%)$ we account for the vast majority of the papers. It is also interesting to note that while sparsely represented 22 method and purpose combinations can be found within the ISWC literature from the past five years.

In Figure 1 the classified methods and purposes are detached and normalized by the number of submissions per year. In methods, we observe a trend of a small decline in Applied Research and Field Studies and see growth mainly in Lab Experiments. Interestingly, this trend is opposite to that in End-User Development, where natural setting studies are increasingly prominent at the expense of Lab Experiments [16]. In purposes, we observe a decline in re-engineering while there is an increase in describing and understanding. While five years of data may be too short a time to observe a 

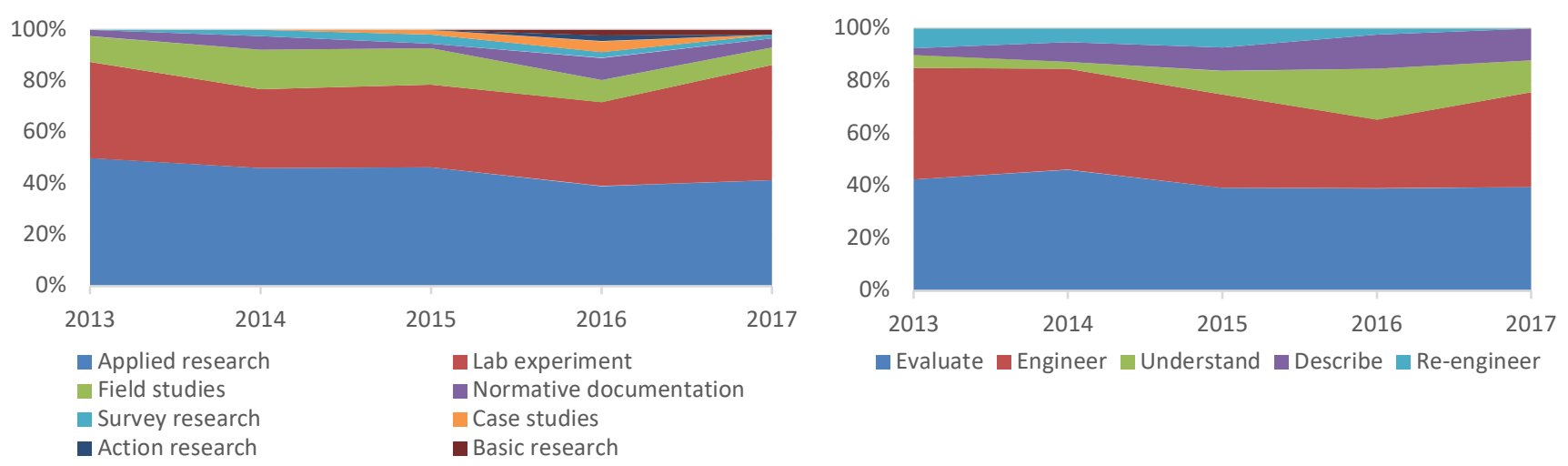

Figure 1: Method and purpose classifications are observed by year, normalized for number of submissions per year.

definite trend, looking at the normalized methods and purposes individually reveals shifts in the ISWC literature.

\section{Research Domains}

In the thematic analysis of Research Domains we see a broad number of domains that are generally growing over time. The count of identified research domains was 29 in 2013, 37 in 2014, 47 in 2015, 46 in 2016 and 51 in 2017. Counts by Domain by year can be seeing in Figure 2, only domains with three or more classifications are shown. Domains Animals, Assistive technology, Modelling, Navigation, Olfaction, Skiing, and Table tennis have 2 counts. Domains Communication, Document Classification, Firefighting, Jewelry, Localization, Security, Self-defense, Sleep, Telepresence, and Tracking have 1 count. While five years is too brief of a period to determine trends, we do see the domains Input, Personal Activity, Gesture and Textiles remaining solid over all five years. The domains Output, Sensing, Haptics and Design have been growing over the survey period. Group Activity has shown a decline in publications.

\section{Impact of publications}

In this section, we look at the citations attributed to each publication and how the classifications correspond. Looking at citations documented in the ACM Digital Library provides insights to the research method/purpose/domain impact over time. Publications from 2017 have no citations as they were new at the time this literature survey was made (March 2018). We find 56 citations for 21 publications in 2016 (2.67 citations/publication, $\mathrm{SD}=2.15), 107$ citations for 30 publications in 2015 (3.57 citations/publication, $\mathrm{SD}=3.01$ ), 73 citations for 21 publications in 2014 (3.48 citations/publication, $\mathrm{SD}=2.11$ ) and 211 citations for 20 publications in 2013 (10.55 citations/publication, $\mathrm{SD}=9.91$ ). In general, older publications tend to acquire more citations. Therefore, in Figure 3 and Figure 4 we compare the number of classified publications to average citation counts, normalized for the age of a publication (citation counts for papers are divided by the number of years before 2018).

\section{Research method and purpose}

Looking at citations by classification provides insight into the impact of the research. We see that most research aimed at providing an Understanding of a context or design space (AR-UN, ND-UN, SR-UN and FS-UN in particular) attracts more citations (avg. 1.75 citation per paper, normalized for age) than research aimed at Engineering (avg. 1.09),

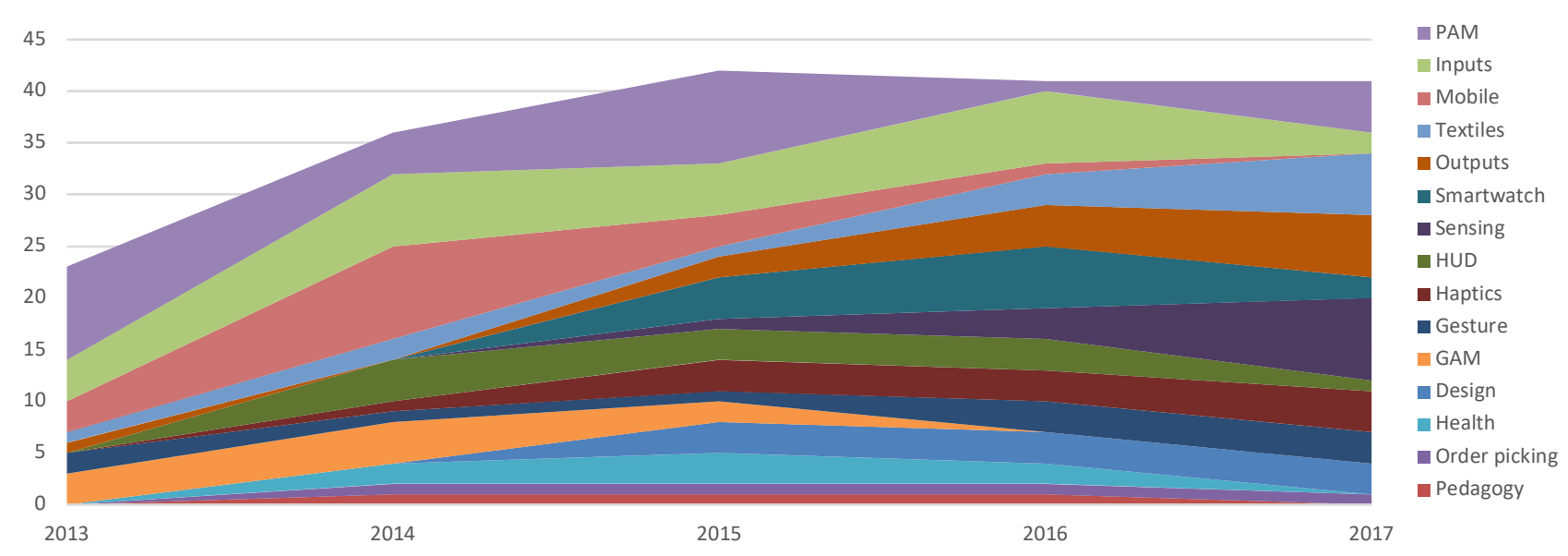

Figure 2: Domain classifications per year. Only domains that have at least 3 classifications are represented in this graph. 


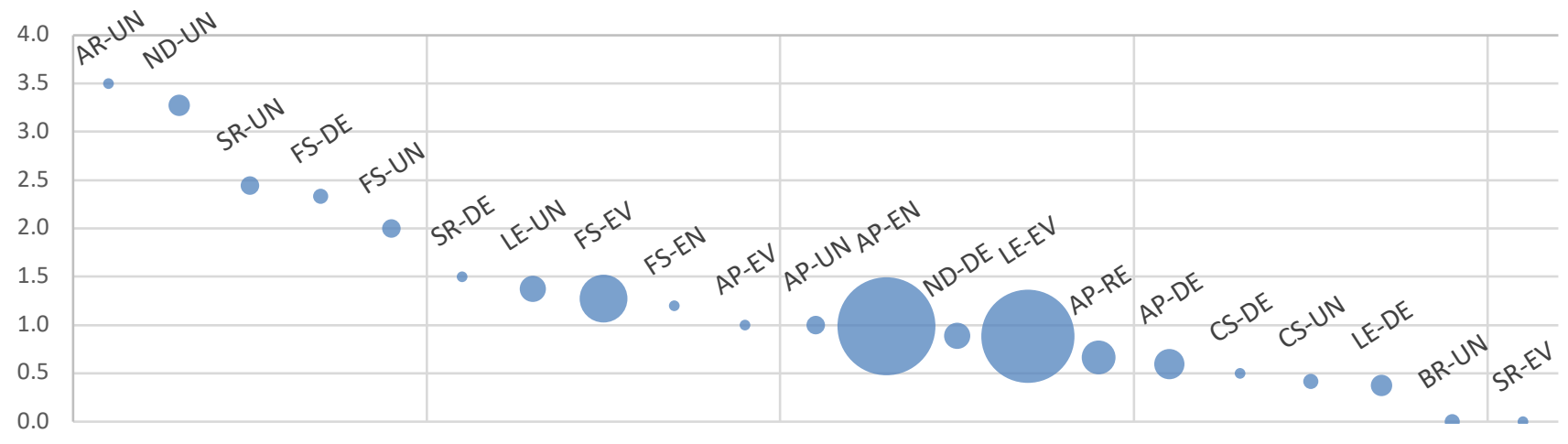

Figure 3: Average citations for publications per classification. The vertical axis shows the average citation count per classification, normalized for publication age. The bubble size indicates the number of publications with a certain classification.

Describing (avg. 1.03), Evaluating (avg. 0.79) or ReEngineering (avg. 0.67).

When considering the research method that is applied, Action Research is most highly cited (avg. 3.50 citation per paper, normalized for age), followed by Normative Documentation (avg. 2.08), Field Study (avg. 1.70), Survey Research (avg. 1.31), Lab Experiment (avg. 0.88), Applied Research (avg. 0.85), Case Study (0.45) and Basic Research (avg. 0.00). Note that there are only few papers with classification Action Research, Case Study and Basic Research, which might provide a biased picture of their relative impact. Nonetheless, it is interesting to see that Field Study research has much higher impact than Lab Experiments. Evaluations performed as Field Studies (FS$\mathrm{EV}$, avg. 1.3 citations) also tend to acquire more citations than those as Lab Studies (LE-EV, avg. 0.9 citations).

\section{Domains}

Considering the number of citations by domain we see the following citations counts by domain: Inputs 127, Personal Activity Monitoring (PAM) 123, Mobile 71, Smartwatch 53, Textile 36, Gesture 29, Design 28, HUD 27, Animals 27, Group Activity Monitoring (GAM) 24, Haptics 23, Outputs 22, Health 20, Document Classification 15, Tracking 15, Navigation 14, Sensing 13, Order Picking 9, Telepresence 7, Pedagogy 6, Table Tennis 6, Firefighting 6, Jewelry 4, Assistive Technologies 2, VR 2 and Localization 1. To gain more insight we look at the average number of citations for each domain, while normalizing for the age of the publication. Figure 4 shows average citations over number normalized by year of publication. Some domains see high normalized citation rates: Document Classification 3.0, Tracking 3.0, and Animals 2.8. Most of the publications from larger domains score between 0.5 and 1.4 normalized citations on average, with a notable exception for publications on Smartwatch related research (avg. 1.8).

\section{DISCUSSION}

Comparing the classification of the 119 publications of ISWC to the earlier classifications using similar schema from Mobile HCI, Interaction Design and Children and End User Development we find the following. It is interesting that the majority of research publications surveyed fall into the Applied Research-Engineering, Lab Experiment-Evaluation, and Field Study-Evaluation categories not only in the ISWC field, but also in the earlier surveys $[5,7,16]$. The corresponding survey papers all similarly highlight opportunities for natural setting research. Design research through practice [8] describes how to do this. It is also interesting to see that there is a higher number of papers combining different research methods/purposes in the ISWC research compared to the other fields. Only 14 out of the 119 papers, $15 \%$, have a single classification. This indicates a dynamic and multi-disciplinary nature of the field, which should foster cross-fertilization and innovation.

The tendency of a greater number of citations for papers that classify to the purpose of understanding appears promising. More citations can be expected for the 2017 publications.

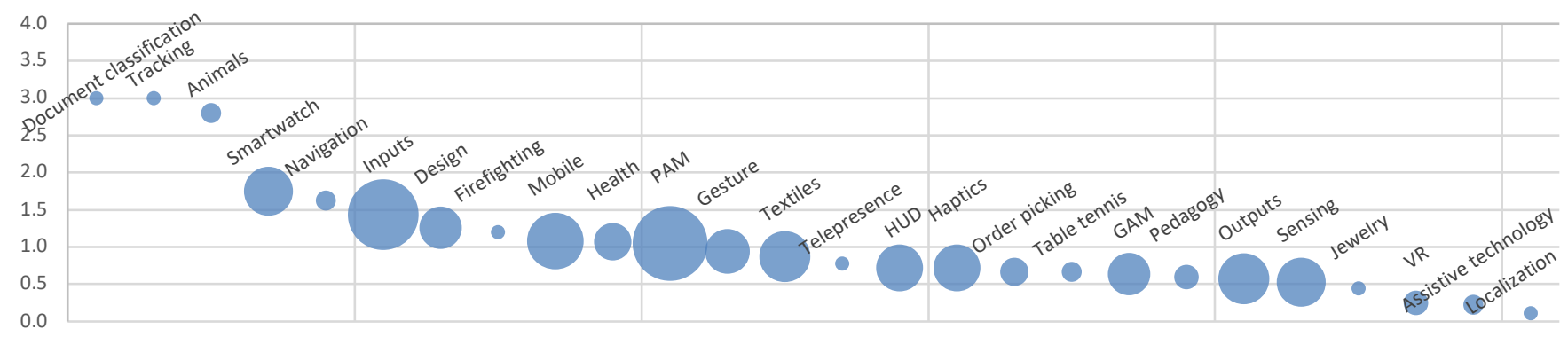

Figure 4: Average citations for publications per domain, normalized for the age of a publication. Domains without citations have been omitted from this figure. The bubble size indicates the number of papers within a certain domain. 
The growth in the Describing research purpose in 2016 and 2017 is also of note and should be reflected upon in future surveys. It will be interesting to observe how this progresses and if it is a sign of growth and longevity of the field.

Normative documentation and applied research allow for knowledge in design archetypes as prototypes [21]. This was seen not only in the considered publications, but also in the design exhibition adjunct proceedings of ISWC. The Design Exhibition publications were excluded from this survey, but the publications all contain prototypes that could be important to survey.

While different methods are relatively uniformly represented in the survey, the purposes seem unbalanced. Engineering and Re-Engineering as different purposes provides too much detail in comparison to the other very general terms. A solution would be to merge engineering and re-engineering into the same category.

\section{LIMITATIONS}

The publications surveyed are not written with the schema in mind and authors do not necessarily subscribe to these terms. Despite the best efforts of the coders to analyze, debate, reread and re-analyze the publications, methods, purposes and domains are not always clear. Examples of research methods being labeled as one method by the publication author that did not fit the scheme definition were found [14]. This reflects the diverse terminology that is inherent in a multidisciplinary field of research

We were cautious when making comparisons to other similar surveys in HCI $[5,7,16]$. There is very little to no overlap in the time period covered. It could be instructive to make such a comparison of classifications of research methods and purposes in different fields covering the same time.

In citations, no data was available in the ACM digital library for 2017 when the study was conducted. More than this, the publications discussed in this paper might have been cited by sources not tracked by the ACM digital library. The values used for this paper thus represent lower bounds on the actual citation numbers.

There is a design process of exploring that is not well represented in the model. Prototypes are a form of exploring and a "Means of inquiry" Wensveen and Matthews [21]. Exploration was integrated into the purpose of describing in this survey but may be a research purpose in itself. Although this was not explicitly clear in the surveyed literature.

The classification schema continues to evolve and we hope others will join in the survey of other HCI fields and communities. The research shows that there is opportunity to build a larger understanding of research that is more generalizable, build frameworks, and generate theory. That will require more than a survey into five years of ISWC.

While we have attempted to be complete and include the most informative analysis in this survey, we realize that additional analyses of our data might reveal more insights.
Therefore, we encourage fellow researchers to explore our source data, which we included as appendix to this paper, for further analysis and as inspiration for future surveys.

\section{CONCLUSION}

A survey of 119 publications of the International Symposium on Wearable Computers (ISWC) from 2013 to 2017 was conducted. After over twenty years of ISWC, we see a conference that is going strong. Research Methods, Purposes and Domains are surveyed using thematic analysis of domains and applying an adapted version of the Wynekoop and Conger classification schema of Research Methods and Purposes [22] previously used in HCI surveys [5,7,16]. Our results show that ISWC has a strong disposition towards publications with applied research methods for engineering purposes. This is most often evaluated using lab experiment methodology. These research method and purposes are similar to surveys of other HCI related fields. In our research, we see a strong preference for artificial setting research (lab experiments) although recent ISWC research that uses natural settings (i.e. Field studies) has a higher impact in terms of citations. Also, papers classified with the research purpose of understanding have a higher number of citations on average.

The survey shows there is opportunity to improve the ecological validity of existing knowledge. This opportunity lies outside of the artificial setting of the lab environment. Natural setting research methods allow for greater knowledge in context or societal implications. The increase of citations for Field studies invites researchers in the field to explore if other natural setting research [1], Case studies, and Action research, would yield similar results in citations.

This survey expands on previous definitions of research methods and purpose to clarify the evolution of understanding of prototypes and design research. The most cited paper of our survey [14] presents a prototype as a research archetype. It classifies as a Lab Experiment for Understanding even though it has case study in the title. The definitions of this type of survey will need even more change. This survey adds the dimension of domains to bring more context to the field and community to help others understand.

Although the research presented at ISWC is primarily classified as Applied Research for Engineering and Lab Experiments for Evaluation, it is important to note that all methods and purposes are represented in the classification. This in contrast to the earlier literature surveys in different research fields mentioned above. This survey of ISWC shows a conference with a strong core that is open to many methods, purposes, and domains of research. It shows the impact of ISWC not only in engineering/evaluating but also in understanding and description in natural settings.

\section{REFERENCES}

1. Izak Benbasat. 1985. An analysis of research methodologies. Boston: Harvard Business School Press. 
2. Lucy E Dunne, Halley Profita, Clint Zeagler, James Clawson, Scott Gilliland, Ellen Yi-Luen Do, and Jim Budd. 2014. The social comfort of wearable technology and gestural interaction. In Proc. of EMBC '14 IEEE, 4159-4162.

3. William Gaver. 2012. What should we expect from research through design? In Proc. of CHI '12, 937. https://doi.org/10.1145/2207676.2208538

4. M. Jackson, C. Zeagler, G. Valentin, A. Martin, V. Martin, A. Delawalla, W. Blount, S. Eiring, R. Hollis, Y. Kshirsagar, and T. Starner. 2013. FIDO facilitating interactions for dogs with occupations. In Proc. of ISWC '13, 81-88. https://doi.org/10.1145/2493988.2494334

5. Jj Jensen and Mb Skov. 2005. A review of research methods in children's technology design. Proc. of IDC '05: 318-324. https://doi.org/10.1145/1109540.1109551

6. Hsin-Liu Cindy Kao, Christian Holz, Asta Roseway, Andres Calvo, and Chris Schmandt. 2016. DuoSkin: rapidly prototyping on-skin user interfaces using skin-friendly materials. In Proc. of ISWC '16, 16-23. https://doi.org/10.1145/2971763.2971777

7. Jesper Kjeldskov and Connor Graham. 2003. A Review of Mobile HCI Research Methods. Proc. of Mobile HCI '03: 317-335. https://doi.org/10.1007/978-3-540-45233-1_23

8. Ilpo Koskinen, John Zimmerman, Thomas Binder, Johan Redström, and Stephan Wensveen. 2012. Design Research Through Practice. https://doi.org/10.1016/B978-0-12-3855022.00010-9

9. Kent Lyons. 2015. What can a dumb watch teach a smartwatch? In Proc. of ISWC '15, 3-10.

10. Angella Mackey, Ron Wakkary, Stephan Wensveen, and Oscar Tomico. 2017. “ Can I Wear This?" Blending Clothing and Digital Expression. International Journal of Design 11, 3 .

11. Sergio R. Munoz and Shrikant I. Bangdiwala. 1997. Interpretation of Kappa and B statistics measures of agreement. Journal of Applied Statistics 24, 1: 105112. https://doi.org/10.1080/02664769723918

12. Troy Nachtigall. 2017. EVA Moccasin: creating a research archetype to explore shoe use. In Adj. Proc. of ISWC '17, 197-202. https://doi.org/10.1145/3123021.3123077

13. William Odom, Ron Wakkary, Youn-kyung Lim, Audrey Desjardins, Bart Hengeveld, and Richard Banks. 2016. From Research Prototype to Research Product. In Proc. of CHI '16, 2549-2561. https://doi.org/10.1145/2858036.2858447
14. Halley P. Profita, James Clawson, Scott Gilliland, Clint Zeagler, Thad Starner, Jim Budd, and Ellen YiLuen Do. 2013. Don't mind me touching my wrist: a case study of interacting with on-body technology in public. In Proc. of ISWC '13, 89-96. https://doi.org/10.1145/2493988.2494331

15. Gabriel Reyes, W Keith Edwards, Dingtian Zhang, Sarthak Ghosh, Pratik Shah, Jason Wu, Aman Parnami, Bailey Bercik, Thad Starner, and Gregory D Abowd. 2016. Whoosh: non-voice acoustics for low-cost, hands-free, and rapid input on smartwatches. In Proc. of ISWC '16, 120-127. https://doi.org/10.1145/2971763.2971765

16. Daniel Tetteroo and Panos Markopoulos. 2015. A Review of Research Methods in End User Development. IS-EUD '15 9083: 58-75. https://doi.org/10.1007/978-3-319-18425-8_5

17. Oscar Tomico, Lars Hallnäs, Rung-Huei Liang, and Stephan Wensveen. 2017. Towards a next wave of wearable and fashionable interactions. International Journal of Design 11, 3: 1-6.

18. Oscar Tomico and Danielle Wilde. 2016. Soft, embodied, situated \& connected: enriching interactions with soft wearables. $m U X$ : The Journal of Mobile User Experience 5, 1: 3.

19. Giancarlo Valentin, Joelle Alcaidinho, Ayanna Howard, Melody M. Jackson, and Thad Starner. 2016. Creating collar-sensed motion gestures for dog-human communication in service applications. In Proc. of ISWC '16, 100-107. https://doi.org/10.1145/2971763.2971788

20. Ron Wakkary, Doenja Oogjes, Henry W J Lin, and Sabrina Hauser. 2018. Philosophers Living with the Tilting Bowl. In Proc. of CHI '18, 94.

21. Stephan Wensveen and Ben Matthews. 2015. Prototypes and Prototyping in Design Research. Routledge Companion to Design Research: 262-76.

22. J L Wynekoop and S Conger. 1990. A review of computer aided software engineering research methods. The Information Systems Research Arena of the 90s Challenges Perceptions and Alternative Approaches 1: 129-154.

23. Robert K. Yin. 2012. Case Study Research Design and Methods. Sage Publications Sage UK: London.

24. Clint Zeagler. 2017. Where to Wear it: functional, technical, and social considerations in on-body location for wearable technology 20 years of designing for wearability. In Proc. of ISWC '17, 150-157. https://doi.org/10.1145/3123021.3123042 